\title{
The Phys-Can observational study: adjuvant chemotherapy is associated with a reduction whereas physical activity level before start of treatment is associated with maintenance of maximal oxygen uptake in patients with cancer
}

Tor Helge Wiestad ${ }^{1 *}$ (D), Truls Raastad ${ }^{2}$, Karin Nordin ${ }^{3,4}$, Helena Igelström5, Anna Henriksson ${ }^{4}$, Ingrid Demmelmaier ${ }^{4}$ and Sveinung Berntsen ${ }^{3,4}$

\begin{abstract}
Background: Adjuvant therapy may cause multiple sideeffects on long term health, including reduced cardiorespiratory fitness (CRF) in patients with breast cancer $(1,2)$. However, there is currently limited knowledge regarding the effect of different types of adjuvant cancer treatment on CRF in other cancer populations. The primary objective of the present study was to assess whether previously known correlates (age, diagnosis, initial CRF, physical activity level), type of adjuvant treatment and cancer-related fatigue were associated with changes in $\mathrm{VO}_{2}$ max in patients with breast, prostate or colorectal cancer.
\end{abstract}

Methods: Prospective study with two time points of assessment, 85 patients scheduled for adjuvant cancer treatment were included. Cardiorespiratory fitness was assessed by $\mathrm{VO}_{2}$ max during a maximal incremental exercise test on a treadmill before start of adjuvant therapy and again six months later. Physical activity level was recorded with a physical activity monitor (Sense Wear ${ }^{\mathrm{TM}}$ Mini) at baseline as average minutes of moderate-to-vigorous intensity physical activity (MVPA) per day. Physical fatigue at baseline was reported using the Multidimensional Fatigue Inventory-20 questionaire.

Results: In multivariate linear regression analysis, 30 min higher daily MVPA at baseline was associated with a 5\% higher $\mathrm{V}_{2}$ max at six months follow up when adjusted for adjuvant treatment $(P=0.010)$. Patients receiving adjuvant chemotherapy had a mean decline in $\mathrm{VO}_{2}$ max of $10 \%(-19,-1 ; 95 \%$ confidence interval) compared to patients receiving adjuvant endocrine treatment $(P=0.028)$. Adjuvant radiotherapy, fatigue, age and diagnosis were not significantly associated with changes in $\mathrm{VO}_{2}$ max.

* Correspondence: tor.helge.wiestad@helse-bergen.no

'Department of Oncology and Medical Physics, Haukeland University Hospital, Box 1400, 5021 Bergen, PO, Norway

Full list of author information is available at the end of the article

C C The Author(s). 2020 Open Access This article is licensed under a Creative Commons Attribution 4.0 International License, which permits use, sharing, adaptation, distribution and reproduction in any medium or format, as long as you give appropriate credit to the original author(s) and the source, provide a link to the Creative Commons licence, and indicate if changes were made. The images or other third party material in this article are included in the article's Creative Commons licence, unless indicated otherwise in a credit line to the material. If material is not included in the article's Creative Commons licence and your intended use is not permitted by statutory regulation or exceeds the permitted use, you will need to obtain permission directly from the copyright holder. To view a copy of this licence, visit http://creativecommons.org/licenses/by/4.0/. The Creative Commons Public Domain Dedication waiver (http://creativecommons.org/publicdomain/zero/1.0/) applies to the data made available in this article, unless otherwise stated in a credit line to the data. 
(Continued from previous page)

Conclusion: The results of the present study indicate that adjuvant chemotherapy is associated with a subsequent reduction in $\mathrm{VO}_{2}$ max in patients with cancer whereas MVPA before start of adjuvant treatment is positively associated with a higher $\mathrm{V}_{2}$ max after end of adjuvant treatment.

Keywords: Cardiopulmonary exercise testing, Physical activity, Oncological treatment, Cancer related fatigue

\section{Background}

Althought cancer treatments have documented effects on survival, they can be invasive and toxic and cause multiple potential negative sideeffects on long term health including reduced physical functioning, impaired quality of life, chronic fatigue and reduced cardiorespiratory fitness (CRF) $[1,2]$.

$\mathrm{CRF}$, assessed by measurement of the maximal oxygen uptake $\left(\mathrm{VO}_{2} \max \right)$, quantifies an individual's maximal aerobic power and provides valuable diagnostic and prognostic information about cardiovascular function, cardiopulmonary reserve, and efficiency of oxygen transport and utilization and can disclose compensatory mechanisms of abnormal cardiac function [3]. Previous studies have shown that CRF in patients with cancer is around $30 \%$ lower compared to healthy age- and sexmatched people [4-6]. In a recent meta-analysis it is implied that CRF in patients with breast cancer decreases with approximately $10 \%$ during cancer treatment and that reduced CRF can be measured even seven years after end of chemotherapy treatment [7]. These findings are of major concern given that low CRF is an important risk factor for cardiopulmonary disease and mortality in both healthy individuals and patients with cancer $[8,9]$. Sufficient $\dot{V} O_{2}$ max is related to fewer toxic effects of radiotherapy, chemotherapy, and endocrine therapy on the cardiovascular system, respiratory system, and skeletal muscles [10-15], and higher physical activity level and daily functioning in patients with cancer [16].

Physical activity (PA) is recommended as a strategy both during and after adjuvant treatment to manage treatment-related symptoms, prevent early and late comorbidities and improve quality of life [17, 18]. Studies has shown that physical activity, especially structured training programs, can contribute to increase or maintain CRF, increase muscle strength, and improve cancer related fatigue $[18,19]$. Cancer related fatigue is a common adverse effect reported in up to $99 \%$ of all cancer patients receiving adjuvant treatment in the form of radiation therapy, chemotherapy or/and biological therapy [20]. Cancer related fatigue causes a sense of physical, emotional and/or cognitive tiredness in patients which is not proportional to recent activity, and interferes with patients usual functioning [21]. Unfortunately, studies including self-reports of PA levels among patients with cancer, have shown that patients reduce their PA levels from prior to diagnosis to start of adjuvant treatment [22], and that PA levels decrease significantly during adjuvant therapy [16]. In addition, similar to healthy adults, patients with cancer are subject to the effects of ageing and age-related deconditioning that adversely affect components of the oxygen cascade and lead to reduced tolerance for exercise [13]. However, in patients with cancer, these consequences are compounded by the effects of cancer therapies leading to reductions in exercise tolerance [13].

Despite evidence that low CRF is a sign of poor prognosis for cardiopulmonary disease and mortality in both healthy individuals and patients with cancer $[8,9]$, there is currently little known regarding the effect of different types of adjuvant cancer treatment on $\mathrm{VO}_{2} \max$ in different cancer populations. Furthermore, the existing literature has several important methodological limitations like inconsistent assessment of physical activity across studies, prediction or determination of cardiorespiratory fitness from submaximal exercise tests, and incomplete consideration of variation of effects across population subgroups (for example, defined by BMI, age or sex), and sufficient considerations to other factors that may explain study results. Knowing the effect of different types of adjuvant cancer therapy on CRF is important to elucidate therapy-related decrements in $\mathrm{CRF}$ and for preventing further impairment.

Important clinical implications can arise from assessing CRF in patients with cancer, and identifying correlates associated with change in CRF. Along with data from the Phys-Can randomized-controlled trial study [23], knowledge from this study may also help to improve the specificity of exercise prescriptions to different patients with cancer based on their treatment regime. The overall long term goal would be to use this knowledge to individualize and optimize physical activity recommendations in order to maintain $\mathrm{VO}_{2}$ max during the adjuvant phase of cancer treatment.

The primary objective of the present study was to identify correlates of changes in $\mathrm{VO}_{2} \max$ in patients undergoing adjuvant treatment for breast, prostate or colorectal cancer. More specifically, we aimed to assess whether previously described correlates (age, diagnosis, initial CRF, physical activity level), type of adjuvant 
treatment and cancer-related fatigue were associated with changes in $\mathrm{VO}_{2} \max$ in patients with breast, prostate or colorectal cancer.

\section{Methods \\ Study design}

The present study was a multi-center, prospective, observational cohort study investigating changes in cardiorespiratory fitness in patients undergoing adjuvant treatment for cancer without any specific exercise intervention; "The Phys-Can (Physical training and Cancer) observational study". The included patients were intended to act as controls to those patients later recruited to the Phys-Can randomized controlled intervention study. Phys-Can has previously been described in detail [23]. Participants in the observational study received care as usual, including advice about being physically active during treatment, but were not offered to participate in an exercise intervention.

Patients aged $\geq 18$, recently diagnosed with breast cancer, colorectal cancer or prostate cancer, scheduled for neoadjuvant chemotherapy (breast cancer) or endocrine therapy (prostate cancer), and/or adjuvant chemotherapy (breast- and colorectal cancer), adjuvant radiotherapy (breast cancer), and/or adjuvant endocrine therapy (breast and prostate cancer) or radiotherapy with curative intent without additional endocrine therapy (prostate cancer) were recruited before start of neoadjuvant/adjuvant cancer treatment. Patients who were unable to understand or express themselves in Swedish, unable to perform basic activities of daily living, showed cognitive disorders or severe emotional instability, or were suffering from other disabling comorbidity that might hamper physical exercise (e.g. unstable angina, severe heart failure, severe chronic obstructive pulmonary disease, orthopedic conditions and neurological disorders) were excluded from the study. In addition patients with breast cancer stage IIIb, men with breast cancer and patients undergoing treatment for other types of malignant disease were excluded from the study.

All patients were assessed by an oncologist or surgeon regarding eligibility to participate in the study. Patients received detailed information both written and verbally, were given ample time to consider their participation and written informed consent was obtained from each participant before entering the study. All tests were conducted before start of adjuvant therapy and again six months after baseline testing. Information on sociodemographic data were collected at baseline only.

The Phys-Can study was registered in ClinicalTrials.gov $($ TRN $=$ NCT02473003, Oct, 2014).
Part of this study has been presented at The Annual Congress of the EUROPEAN COLLEGE OF SPORT SCIENCE, Prague, 2015 [24].

\section{Participants}

Participants were recruited at the University Hospitals in Lund, Linköping and Uppsala in Sweden between September 2014 and March 2015.

Of a total of 237 patients screened, 227 were eligible for the study. Of these, 124 declined participation of various reasons, and 103 accepted participation. One participant dropped out during the inclusion process and another was excluded due to cardiotoxicity, leaving the total number included to 101 participants recently diagnosed with breast $(n=85)$, prostate $(n=12)$ or colorectal cancer $(n=4)$ (Fig. 1). Of the 101 patients included, 85 (84\%) completed baseline testing and 55 (54\%) completed follow-up testing. Only participants with $\mathrm{VO}_{2}$ max data at both baseline and post-test were included in the final analysis.

\section{Measures and procedures Dependent variable}

Cardiorespiratory fitness was assessed by maximal oxygen uptake $\left(\mathrm{VO}_{2} \max \right)$ during an incremental maximal exercise test on a treadmill (Uppsala; Sports Art Fitness, TR33, Tainan, Taiwan, Linköping; GE Healthcare, T2100, USA, Lund; Rodby Innovation, RL2500E, Vänge, Sweden) according to a modified Balke protocol [23]. Participants were instructed not to eat or drink large amounts of liquids two hour before testing, refrain from coffee and nicotine two hours before test, and avoid intensive training the same day and the day prior to the test. Height $(\mathrm{cm})$, weight $(\mathrm{kg})$, blood pressure and heart rate at rest were measured before testing. Participants should not conduct the test if he or she: Ended cytostatic infusion less than $24 \mathrm{~h}$ before the test, experienced chest pains (or pressure), resting dyspnea, feeling faint or dizziness of unknown source, had injuries that could be aggravated by the test, or had a fever or infection at the time of the test. Those participants who got intravenously administered chemotherapy did the follow up CPET earliest a week after ending treatment.

Participants were fitted and familiarized to a two-way breathing mask and headgear (7450 Series V2; Hans Rudolph, Inc.) before stepping on to the treadmill and starting the test. Ventilation and gas exchange variables were measured continuously using a breath-by-breath gas analysis system (Uppsala; Sensor Medics, Vmax 29, Care Fusion, San Diego, USA) or mixing chamber (Lund and Linköping; Oxycon Pro, Erich Jaeger GmbH, Hoechberg, Germany), which was calibrated according 


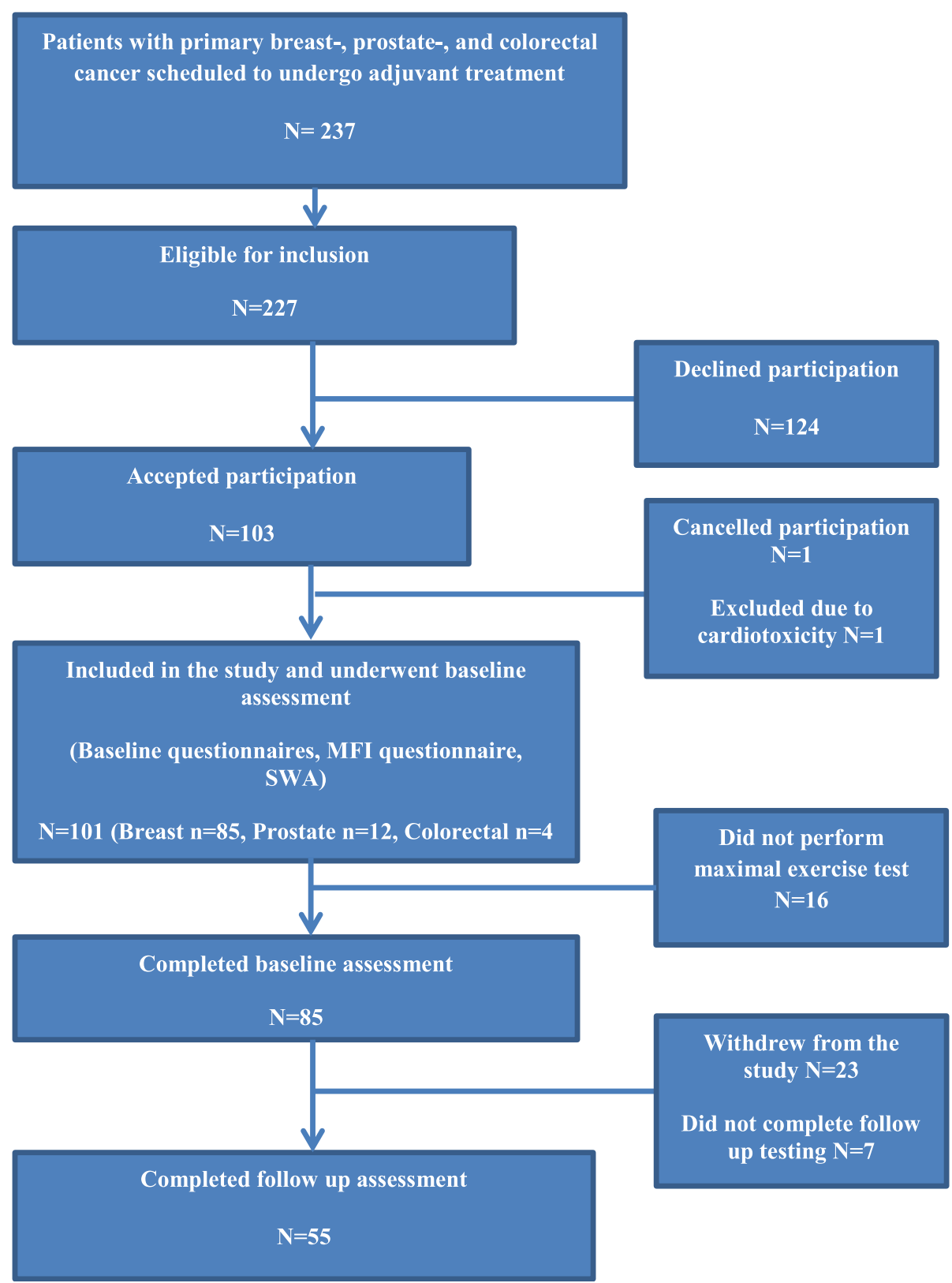

Fig. 1 Flow-chart illustrating participant flow through enrolment, baseline measurement, and follow-up in the present study. Abbreviations: MFI, Multidimensional Fatigue Inventory-20, SWA, Sensewear Armband

to the instructions of the manufacturer before each test. The gas exchange variables were reported as $30 \mathrm{~s}$ averages. Heart rate was measured continuously with a heart rate sensor (Uppsala, Lund) (T34, Polar Electro KY, Kempele, Finland) or a 12-lead ECG recording system (Linköping) (GE Case V6.73. GE Healthcare). The rating of perceived exertion (RPE) was recorded by a standardized Borg-scale [25]. The test continued until volitional exhaustion occurred or the test leader observed indications for terminating the maximal test [26]. After completion of the test the participants walked calmly on the treadmill until ventilation, heart rate levels and leg fatigue normalized. All tests were evaluated after completion and criteria consistent with an accepted $\mathrm{VO}_{2} \max$ where set at Borg $\geq 17$ or RER $\geq 1.1$.

\section{Independent variables}

Physical activity level was objectively monitored with Sense Wear ${ }^{\mathrm{rm}}$ Mini Armband (SWA) (BodyMedia Inc. Pittsburgh, PA, USA) according to manufacturer instructions. SWA has been shown valid compared to double 
labeled water in healthy adults [27] and compared to indirect calorimetry in both healthy adults [28] and patients with cancer [29]. Participants were instructed to wear the SWA for seven consecutive days, and only remove it during water-based activities. Data from the SWA was downloaded and analyzed with software developed by the manufacturer (Sense Wear Professional Research Software V.8.1, Algorithm V2.2.4).

In the present study average minutes of moderate-tovigorous intensity physical activity (MVPA) per day at baseline were included. The SWA was programmed to record PA in 1-min epochs. The cut-points defined MVPA as $\geq 3$ METs according to Garber et al. [30].

Cancer related fatigue was reported using the Multidimensional Fatigue Inventory-20 (MFI) questionaire [31] at baseline. The MFI is a validated self-report questionnaire that has been used to assess fatigue in patients with a variety of cancers [32]. It consists of 20 items grouped into five subscales representing general fatigue, physical fatigue, reduced activity, reduced motivation and mental fatigue. The MFI has been reported to be a valid and reliable (average Cronbach's alpha $=0.84$ ) instrument for use amongst people with cancer [31]. For the present study we were interested in physical fatigue at baseline as it may hinder physical activity and in turn affect $\mathrm{VO}_{2}$ max. Cut point for determining physical fatigue was based on work by Hagelin et al. [32] and Purcell et al. [33] and were set at scores $>10.4$ on the physical fatigue subscale.

Health-related data on cancer diagnosis and primary adjuvant treatment were collected from medical records at baseline.

Sociodemographic data on age, sex, education, work situation, living conditions, and sick leave was collected from study-specific questionnaires.

\section{Statistical analysis}

Descriptive characteristics are presented as mean values with standard deviation (SD) unless otherwise stated and results as mean with $95 \%$ confidence intervals (CI).

Between-group differences were analyzed with Wilcoxon Signed Ranks test due to lack of assumption about normality and homogeneity of variance.

Multivariate linear regression models were applied to assess whether age, diagnosis group, type of adjuvant treatment, MVPA at baseline and physical fatigue at baseline were associated with changes in $\mathrm{VO}_{2}$ max. Diagnosis group was recoded into two categories; "breast cancer" and "prostate and colorectal cancer" due to few participants in the two latter groups. Type of adjuvant treatment was coded into three categories; "adjuvant chemotherapy treatment", "radiotherapy treatment" and "endocrine therapy treatment". Physical fatigue at baseline was coded as "physical fatigue at baseline" or "no physical fatigue at baseline".
The final multivariate model was built as described by Hosmer and Lemeshow [34]. This means that all independent variables with $P \leq 0.2$ in the bivariate analysis were included in the multivariate analysis. Adjuvant radiation therapy was included in the multivariate analysis despite $P \geq 0.2$ because type of adjuvant treatment was recoded into three design variables and adjuvant chemotherapy treatment had a $P \leq 0.2$. Also, type of adjuvant treatment is known to be a clinically important variable for $\mathrm{VO}_{2} \max$ in breast cancer patients [8]. In the multivariate analysis the least significant variable from the bivariate analysis was removed in a step-wise fashion and the analyses were performed again. This removed age and no physical fatigue. The procedure was repeated until only significant independent variables remained. Adjuvant treatment and MVPA were not removed from the final model.

The IBM SPSS version 22.0 statistical software program (Statistical Product and Service Solutions, Chicago, IL, USA) was used for all analysis. The level of significance was set to 0.05 .

\section{Results}

Table 1 shows the characteristics of the study participants at baseline stratified by $\mathrm{VO}_{2} \max$ measurement at both baseline and six months compared to baseline only.

Participants with and without follow up $\mathrm{VO}_{2} \max$ measurements were similar with respect to age, height, weight, cohabitation, education level, working status and diagnosis. Physical fatigue was reported by $94 \%$ of participants at baseline. There were no differences in MVPA levels between diagnosis groups at baseline.

In linear regression analysis, fatigue, age and diagnosis were not associated with changes in $\mathrm{VO}_{2}$ max during treatment. MVPA at baseline and adjuvant treatment explained $23 \%$ of the variability in changes in $\mathrm{VO}_{2}$ max (Table 2).

A 30 min higher MVPA before start of adjuvant treatment was associated with a $5 \%$ higher $\mathrm{VO}_{2} \max$ $(P=0.010)$ at six months follow up when adjusted for adjuvant treatment (Table 2). Adjuvant chemotherapy treatment was associated with a reduction in $\mathrm{VO}_{2} \max$ $(P=0.028)$. Patients receiving adjuvant chemotherapy treatment had a mean decline in $\dot{V O}_{2}$ max of $10 \%$ (-19, $-1.1,95 \% \mathrm{CI}$ ) compared to patients receiving adjuvant endocrine therapy treatment only. Adjuvant radiotherapy and endocrine therapy were not associated with changes in $\mathrm{VO}_{2}$ max.

Table 3 shows average $\dot{V} O_{2}$ max, peak $\dot{V}$ E, HR, RER and RPE from the maximal exercise test at baseline and six months after start of adjuvant treatment for the different treatment groups. There was a significant increase 
Table 1 Baseline characteristics of participating subjects with $(n=55)$ and without $(n=30)$ maximal oxygen uptake measurements before and six months after start of adjuvant cancer treatment. Results are presented as frequencies and percentages in parenthesis unless otherwise stated*

\begin{tabular}{|c|c|c|}
\hline & Baseline and follow up $n=55$ (64.7) & Baseline only $n=30(35.3)$ \\
\hline Age yrs., mean (SD) & $58.8(11.1)$ & $59.2(12.9)$ \\
\hline Height cm, mean (SD) & $168(7.7)$ & $167(5.6)^{\mathrm{a}}$ \\
\hline Weight kg, mean (SD) & $74.3(14)$ & $75.2(16)^{a}$ \\
\hline Females, n (\%) & $42(80.8)^{b}$ & $27(90)$ \\
\hline Cohabitation & $\mathrm{b}$ & \\
\hline Married/cohabitant, n (\%) & $42(80.8)$ & $21(70)$ \\
\hline One couple, two households, n (\%) & $3(5.8)$ & $3(10)$ \\
\hline Living alone, n (\%) & $7(13.5)$ & $6(20)$ \\
\hline Education level, n (\%) & c & \\
\hline Compulsory school, n (\%) & $4(7.8)$ & $4(13.3)$ \\
\hline High School, n (\%) & $17(33.3)$ & $8(26.7)$ \\
\hline College/university n (\%) & $30(58.8)$ & $18(60)$ \\
\hline Working status & $\mathrm{b}$ & \\
\hline Full time work, n (\%) & $15(28.8)$ & $6(20)$ \\
\hline Part time work, n (\%) & $6(11.5)$ & $3(10)$ \\
\hline Retired, Homemaker n (\%) & $20(38.5)$ & $12(40)$ \\
\hline Sick leave, n (\%) & $11(21.2)$ & $9(30)$ \\
\hline \multicolumn{3}{|l|}{ Diagnosis } \\
\hline Breast cancer, n (\%) & $45(81.8)$ & $26(86.7)$ \\
\hline Prostate cancer, n (\%) & $8(14.5)$ & $2(6.7)$ \\
\hline Colorectal cancer, n (\%) & $2(3.6)$ & $2(6.7)$ \\
\hline \multicolumn{3}{|l|}{ Primary adjuvant treatment } \\
\hline Chemotherapy, n (\%) & $20(36.4)$ & $14(46.7)$ \\
\hline \multicolumn{3}{|l|}{ Type chemotherapy ${ }^{d}$} \\
\hline Docetaxcel + FEC low-dose & $9(45.0)$ & \\
\hline Docetaxcel + FEC high-dose & $8(40.0)$ & \\
\hline CAPOX & $1(5.0)$ & \\
\hline Capecitabine single & $1(5.0)$ & \\
\hline Radiation therapy, n (\%) & $18(32.7)$ & $10(33.3)$ \\
\hline Endocrine treatment, n (\%) & $17(30.9)$ & $6(20)$ \\
\hline Physical fatigue, n (\%) & $47(94)^{\mathrm{e}}$ & $28(93.3)$ \\
\hline $\operatorname{MVPA}(\mathrm{SD})^{*}\left(\right.$ min $\left.\mathrm{day}^{-1}\right)$ & $47.6(30.1)^{f}$ & $33.3(19.5)^{9}$ \\
\hline
\end{tabular}

Abbreviations: Docetaxcel, breast cancer only, low-dose $75-80 \mathrm{mg} / \mathrm{m}^{2}$, high-dose $90-100 \mathrm{mg} / \mathrm{m}^{2}$. FEC, breast cancer only, low to high-dose, fluorouracil $500-600$ $\mathrm{mg} / \mathrm{m}^{2}$ and/or only Epirubicin $75-100 \mathrm{mg} / \mathrm{m}^{2}$ and cyclophosphamide $500-600 \mathrm{mg} / \mathrm{m}^{2}$. CAPOX, colorectal only, Capecitabine and Oxaliplatin. Capecitabine single, colorectal only. MVPA, moderate and vigorous physical activity

${ }^{\text {a } M i s s i n g}=5$

${ }^{\mathrm{b}}$ Missing $=3$

${ }^{c}$ Missing $=4$

${ }^{d}$ Missing $=1, \%$ of $n$ participants receiving chemotherapy

e Missing $=5$

${ }^{\mathrm{f}}$ Missing $=7$

${ }^{9}$ Missing $=24$

$(P=0.031)$ in RPE peak from before treatment to six month follow up, from 16.6 to 17.2 , respectively in the radiotherapy group. There were no significant changes in $\dot{V} \mathrm{O}_{2} \max , \dot{V}$ E peak, RER peak, or HR peak.

\section{Discussion}

The results of the present study provide knowledge about clinically relevant correlates to subsequent changes in cardiorespiratory fitness in patients with cancer during 
Table 2 Regression summaries for multivariate analysis with the dependent variable \% change in VO2max from before treatment to six months follow up. The coefficients are given with 95\% confidence intervals

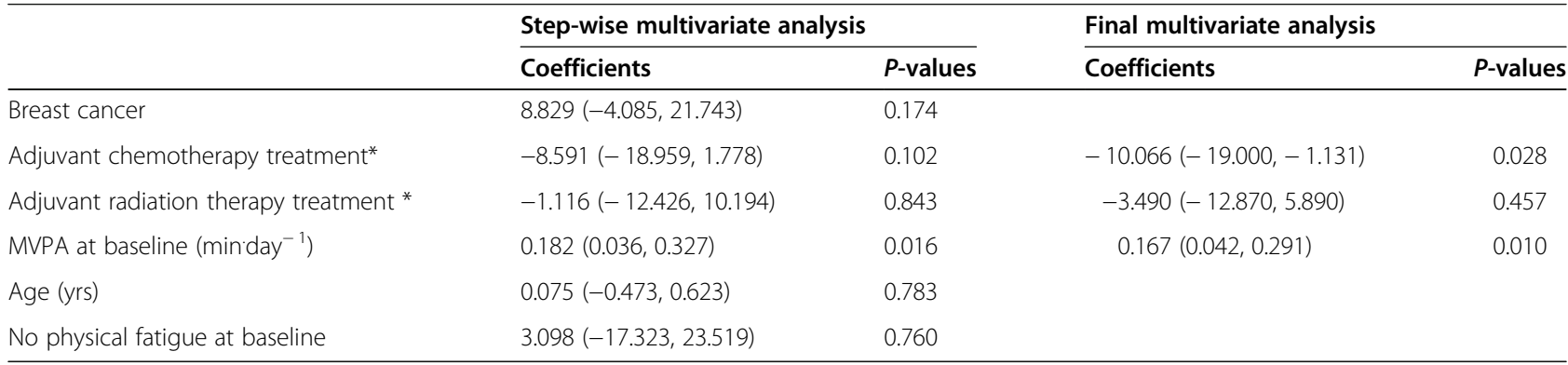

Abbreviations: MVPA; Moderate- to-vigorous physical activity; VO2max; maximal oxygen uptake

${ }^{*}$ Compared to endocrine therapy treatment

adjuvant treatment. Findings indicate that adjuvant chemotherapy treatment is associated with a $10 \%$ decline in $\mathrm{VO}_{2} \max$ six months after start of treatment. The results also indicate that time spent in MVPA before start of adjuvant treatment is associated with higher levels of $\mathrm{VO}_{2}$ max six months later. Fatigue, age and diagnosis were not associated with changes in $\mathrm{VO}_{2}$ max during treatment.

Our results are in line with the work of several other studies examining the association between cancer treatment and cardiorespiratory fitness $[5,8,35,36]$. In a recent meta-analysis including 26 clinical trials and observational studies that measured $\mathrm{VO}_{2}$ max pre- or postadjuvant therapy, it was shown that CRF in patients with breast cancer decreased with approximately 10\% during cancer treatment and that reduced CRF can be measured seven years after end of chemotherapy treatment [7]. In the study by Peel et al. [7], where $78 \%$ of the women were treated with adjuvant chemotherapy, patients with breast cancer had a $17 \%$ lower weighted mean $\mathrm{VO}_{2}$ max prior to adjuvant treatment and a $25 \%$ lower $\mathrm{VO}_{2}$ max after completion of adjuvant therapy compared to healthy sedentary women [7]. In the present study, women treated with adjuvant chemotherapy had a similar $\mathrm{VO}_{2} \max$ prior to adjuvant treatment as healthy age matched women $\left(30.4 \mathrm{ml} \mathrm{kg}^{-1} \cdot \mathrm{min}^{-1}\right)$ [37], but a $8.5 \%$ lower $\mathrm{VO}_{2} \max \left(27.9\left(\mathrm{ml} \mathrm{kg}^{-1} \cdot \mathrm{min}^{-1}\right)\right.$ six months after start of adjuvant chemotherapy treatment compared to healthy age matched women. Our

Table 3 Data from the exercise test of the study participants who completed baseline and follow up testing $(n=55)$ presented by before treatment and after six month follow up, stratified by treatment group. Data are given as mean with confidence intervals (Cl) and standard deviation (SD) in parentheses unless otherwise stated*

\begin{tabular}{|c|c|c|c|c|c|c|}
\hline & & $\begin{array}{l}\text { Before treatment } \\
\text { mean (SD) }\end{array}$ & $95 \% \mathrm{Cl}$ & $\begin{array}{l}\text { Six month follow } \\
\text { up mean (SD) }\end{array}$ & $95 \% \mathrm{Cl}$ & $P$-value ${ }^{\mathrm{b}}$ \\
\hline \multirow[t]{5}{*}{ Chemotherapy $(N=20)$} & VO2max $\left(\mathrm{ml} \mathrm{kg}^{-1} \cdot \mathrm{min}^{-1}\right)$ & $31(7.1)$ & $27.6-34.3$ & $28.7(6.2)$ & $25.8-31.6$ & .191 \\
\hline & VE peak $\left(L \min ^{-1}\right)$ & $84(15.4)$ & $76.8-91.2$ & $82.4(19.4)$ & $73.3-91.5$ & .296 \\
\hline & RER peak & $1.25(0.1)$ & $1.22-1.29$ & $1.22(0.1)$ & $1.17-1.27$ & .147 \\
\hline & RPE peak & $17.2(1.2)$ & $16.6-17.8$ & $17.8(1.2)$ & $17.2-18.3$ & .058 \\
\hline & HR peak (beats. min $^{-1}$ ) & $173(13)$ & $166.5-178.6$ & $170(11.1)$ & $164.3-174.6$ & .054 \\
\hline \multirow[t]{5}{*}{ Radiotherapy $(N=18)$} & $\operatorname{VO} 2 \max \left(\mathrm{ml} \mathrm{kg}^{-1} \cdot \mathrm{min}^{-1}\right)$ & $29.4(6.7)$ & $26.1-32.7$ & $29.4(7.9)$ & $25.5-33.3$ & .794 \\
\hline & VE peak $\left(L \mathrm{~min}^{-1}\right)$ & $77.8(18.7)$ & $68.5-87.1$ & $73.5(28.2)$ & $59.4-87.5$ & .845 \\
\hline & RER peak & $1.20(0.1)$ & $1.15-1.25$ & $1.17(0.1)$ & $1.12-1.23$ & .140 \\
\hline & RPE peak & $16.6(1.3)$ & $15.9-17.2$ & $17.2(1.5)$ & $16.4-17.9$ & $.031^{*}$ \\
\hline & HR peak (beats. min $^{-1}$ ) & $169(20.4)$ & $158.6-178.9$ & $165(16.4)$ & $156.7-173$ & .138 \\
\hline \multirow[t]{5}{*}{ Endocrine therapy $(N=17)$} & VO2max $\left(\mathrm{ml} \mathrm{kg}^{-1} \cdot \min ^{-1}\right)$ & $32(6.8)$ & $28.5-35.5$ & $33.1(9.2)$ & $28.4-37.8$ & .162 \\
\hline & VE peak $\left(L \min ^{-1}\right)$ & $86.6(18.6)$ & $77.1-96.2$ & $83.7(17.2)$ & $74.8-92.5$ & .113 \\
\hline & RER peak & $1.23(0.1)$ & $1.16-1.30$ & $1.19(0.1)$ & $1.13-1.24$ & .162 \\
\hline & RPE peak & $17.4(1.2)$ & $16.8-18$ & $17.2(1.7)$ & $16.3-18.1$ & .558 \\
\hline & HR peak (beats. $\min ^{-1}$ ) & $166(17.8)$ & $156.9-175.2$ & $166(19.7)$ & $156.2-176.4$ & .816 \\
\hline
\end{tabular}

a Abbreviations: VO2max, highest recorded oxygen uptake during exercise test; VE peak, highest recorded ventilation; RER peak, highest recorded respiratory exchange ratio; RPE peak, highest reported perceived exertion; HR peak, highest recorded heart rate; MVPA, Moderate and vigorous physical activity

${ }^{b} P$-values for any differences between groups 
patients had a higher $\hat{V O}_{2} \max$ in both the pre- and post-adjuvant setting compared to the patients in the study by Peel et al. [7], which could be due to differences in testing protocol (treadmill vs. bicycle), but the relative decline of $10 \%$ was similar.

The reason for the decline in $\mathrm{VO}_{2} \max$ in patients treated with adjuvant chemotherapy is likely multifactorial, involving multiple organ components of the oxygen transport chain [7]. Many of these negative effects of chemotherapy are dose dependent, but although treatment regimens are focusing on reducing doses of chemotherapy, there are still several aspects which could reduce $\mathrm{VO}_{2}$ max both directly and indirectly, through reduced physical activity levels. Chemotherapy used in breast cancer treatment are associated with both shortand long term cardiac complications, and anthracyclinebased adjuvant therapy and treatment with trastuzumab in particular, carries a substantial long term risk of heart failure $[4,36]$. Unfavorable alterations in myocardial tissue due to chemotherapy treatment results in reduced left ventricular ejection fraction which in turn reduces convective oxygen delivery [13]. Also, anthracyclinecaused cytotoxic damage leads to compensatory alterations in autonomic tone, which may have implications for the heart rate reserve (HRR) and CRF [38]. However, we did not see any unfavorable changes in heart rate in our patients. Except for the radiotherapy group, all patients reported consistent RPE at both pre- and posttest indicating the same amount of effort. Furthermore, studies have reported negative effects of chemotherapy directly to skeletal muscle $[39,40]$. In these studies, both the force-generating abilities and mitochondrial function are affected negatively and the decrease is dependent upon the length of chemotherapy exposure $[39,40]$.

It has previously been reported that patients reduce their PA levels prior to adjuvant treatment [22], and that $\mathrm{VO}_{2}$ max in cancer patients are already lower prior to adjuvant treatment compared to healthy age matched controls [7]. Our patients had a mean MVPA of 47.6 (30.1) min $^{-1 a y}{ }^{-1}$ prior to adjuvant treatment, which is above the minimum recommended $150 \mathrm{~min}$ of moderate intensity PA per week [17]. However, mean MVPA varied among the participants. We observed that those with mean MVPA less than $30 \mathrm{~min}$ per day before start of adjuvant treatment had a lower mean $\mathrm{VO}_{2} \max$ both prior and after treatment compared to those with mean MVPA > 30 min (results not shown). The group with < 30 min MVPA per day were also the only group with a significant decline in $\mathrm{VO}_{2} \max$ from before start of treatment to six months after. A study on PA among German patients with breast cancer found that PA levels decreased significantly during adjuvant therapy, and the decline was stronger in patients treated with chemoand/or radiotherapy compared to endocrine or no adjuvant therapy [16]. This corresponds to our findings were adjuvant chemotherapy were associated with a decline in $\mathrm{VO}_{2} \max$, possibly due to a reduced PA level in addition to the possible cardiac and direct muscular complications. Alternatively, our results might indicate that a minimum threshold of MVPA before and during treatment can protect against some of the side effects normally observed with adjuvant chemotherapy.

There is evidence that physical activity, even high intensity exercise, is both feasible and safe for patients with cancer both during and after adjuvant treatment $[17,18]$. Patients with cancer participating in exercise programs may increase or maintain their CRF [18], and also, there is evidence that exercise can protect against the acute cardiotoxic effect of anthracyclines and in turn, reduced convective oxygen delivery [41]. Our findings suggest that it could be beneficial to take measures to promote PA to patients with cancer before start of oncological treatment to prevent a decrease in PA level, and consequently a reduced $\mathrm{VO}_{2}$ max. Studies have shown that an oncologist recommendation [42] and physical activity facilities in connection with the hospital [43], might be of importance to increase exercise behavior in newly diagnosed patients.

The present study had a number of strengths, including the inclusion of patients with different cancer diagnosis and type of treatment, the objective measurements of physical activity and direct and maximal testing of cardiorespiratory fitness before start of adjuvant treatment. To our knowledge, few studies have included measured $\mathrm{VO}_{2}$ max in patients with different cancer diagnosis before start of adjuvant therapy [44].

The present study also had several limitations that should be noted. Less than $50 \%$ of the eligible patients completed the study. There was a larger proportion of women and patients with breast cancer among the included patients, and results should be interpreted with caution for patients with colorectal or prostate cancer. Although we did our best to recruit patients with prostate cancer and colorectal cancer, we experienced significant problems in recruiting the two latter groups. Despite the overrepresentation of patients with breast cancer, the distribution between the different cancer therapies (chemotherapy, radiotherapy and endocrine therapy) was evenly distributed, with around 30\% in each treatment group. Our sample consists of patients who are sufficiently fit to participate in such a study, and might be more active than the average patient group resulting in higher $\mathrm{VO}_{2} \max$ values [45]. However, in case of such a bias, real PA and CRF in the overall population of patients with cancer may be even lower than in our study. 


\section{Conclusion}

Adjuvant chemotherapy was associated with a $10 \%$ reduction in $\dot{V} \mathrm{O}_{2}$ max during treatment whereas higher levels of MVPA before start of adjuvant treatment were positively associated with a higher $\mathrm{VO}_{2} \max$ after end of adjuvant treatment. As there was a larger proportion of women with breast cancer among the included patients, we cannot generalize these results to all cancer populations. However, these results combined with previous findings of impaired $\mathrm{VO}_{2} \max$ among patients with cancer [46-49], emphasize the clinical importance of increasing or maintaining $\mathrm{VO}_{2}$ max in this phase of cancer treatment, and highlight the importance of physical activity on cardiorespiratory fitness in patients with cancer. Future studies should address increasing PA in the early phase of treatment and further examine the association between PA and $\mathrm{VO}_{2} \max$, and in particular the underlying mechanisms.

\section{Abbreviations}

RER: Respiratory exchange ratio; Borg RPE Scale: Borg Ratings of Perceived Exertion Scale; Hb: Hemoglobin; HR: Heart rate; HRR: Heart rate reserve; $\dot{V} E$ : Minute ventilation; $\dot{V} \mathrm{O}_{2}$ : Oxygen uptake; $\dot{V} \mathrm{O}_{2}$ max: Maximal oxygen uptake; CPET: Cardiopulmonary exercise test; CRF: Cardiorespiratory fitness; PA: Physical activity; SWA: SenseWear Armband; MVPA: Moderate-to-vigorous intensity physical activity; METs: Metabolic equivalent tasks

\section{Acknowledgements}

Not applicable.

\section{Authors' contributions}

THW wrote the draft of the manuscript, which was revised and edited by SB, $\mathrm{TR}, \mathrm{KN}, \mathrm{AH}, \mathrm{HI}$ and ID several times during the process. THW and SB performed the statistical analyses, and TR, SB and THW specifically contributed to the discussion of physical activity. KN was the principal investigator in the PhysCan study. All authors have substantially contributed to the study, and have read and approved the final manuscript.

\section{Funding}

The present work is performed within the PhysCan study, funded by the Swedish Cancer Society (CAN 2012/621, CAN 2012/631, CAN 2015/414 and The Swedish Research Council (K2014-99X). THW received funds from the department of Oncology and Medical Physics, Haukeland University Hospitals' gift fund to draft the manuscript. The sponsors did not participate in the design or conduct of the study; collection, management, analysis, and interpretation of the data; or in the preparation, review, or approval of the manuscript.

\section{Availability of data and materials}

The datasets used and/or analysed during the current study are available from the corresponding author on reasonable request.

\section{Ethics approval and consent to participate}

All procedures performed in studies involving human participants were in accordance with the ethical standards of the institutional and/or national research committee and with the 1964 Helsinki declaration and its later amendments or comparable ethical standards. This study was part of the Phys-Can intervention study, approved by the Regional Ethical Review Board in Uppsala (EPN D-number 2014/249).and registered in ClinicalTrials.gov (TRN = NCT02473003, Oct, 2014). Patients received detailed information both written and verbally, were given ample time to consider their participation and written informed consent was obtained from each participant before entering the study.

\section{Consent for publication}

Not applicable.

\section{Competing interests}

The authors report no conflicts of interest.

\section{Author details}

${ }^{1}$ Department of Oncology and Medical Physics, Haukeland University Hospital, Box 1400, 5021 Bergen, PO, Norway. ${ }^{2}$ Department of Physical Performance, Norwegian School of Sport Sciences, Oslo, Norway. ${ }^{3}$ Department of Public Health, Sport and Nutrition, Faculty of Health and Sport Sciences, University of Agder, Kristiansand, Norway. ${ }^{4}$ Department of Public Health and Caring Sciences, Uppsala University, Uppsala, Sweden.

${ }^{5}$ Department of neuroscience, Uppsala University, Uppsala, Sweden.

Received: 14 April 2020 Accepted: 31 August 2020

Published online: 03 September 2020

\section{References}

1. Miller KD, Siegel RL, Lin CC, Mariotto AB, Kramer $J$, Rowland JH, et al. Cancer treatment and survivorship statistics, 2016. CA Cancer J Clin. 2016; 66(4):271-89.

2. Scott MJ, Nilsen ST, Gupta WD, Jones WL. Exercise therapy and cardiovascular toxicity in Cancer. Circulation. 2018;137(11):1176-91.

3. Wasserman K. Diagnosing cardiovascular and lung pathophysiology from exercise gas exchange. Chest. 1997;112(4):1091-101.

4. Haykowsky MJ, Mackey JR, Thompson RB, Jones LW, Paterson DI. Adjuvant trastuzumab induces ventricular remodeling despite aerobic exercise training. Clinical cancer research : an official journal of the American Association for Cancer Research. 2009:15(15):4963.

5. Jones LW, Eves ND, Mackey JR, Peddle CJ, Haykowsky M, Joy AA, et al. Safety and feasibility of cardiopulmonary exercise testing in patients with advanced cancer. Lung Cancer. 2007;55(2):225-32.

6. Jones LW, Liang Y, Pituskin EN, Battaglini CL, Scott JM, Hornsby WE, et al. Effect of exercise training on peak oxygen consumption in patients with cancer: a meta-analysis. Oncologist. 2011;16(1):112-20.

7. Peel AB, Thomas SM, Dittus K, Jones LW, Lakoski SG. Cardiorespiratory fitness in breast cancer patients: a call for normative values. J Am Heart Assoc. 2014;3(1):000432.

8. Klassen O, Schmidt ME, Scharhag-Rosenberger F, Sorkin M, Ulrich CM, Schneeweiss A, et al. Cardiorespiratory fitness in breast cancer patients undergoing adjuvant therapy. Acta Oncol. 2014;53(10):1356-65.

9. Laukkanen J, Kurl S, Salonen J. Cardiorespiratory fitness and physical activity as risk predictors of future atherosclerotic cardiovascular diseases. Curr Atheroscler Rep. 2002:4(6):468-76.

10. Suter TM, Ewer MS. Cancer drugs and the heart: importance and management. Eur Heart J. 2013;34(15):1102-11.

11. Shan K, Lincoff A, Young J. Anthracycline-induced cardiotoxicity. Ann Intern Med1996. p. 47-58.

12. Eickmeyer SM, Gamble GL, Shahpar S, Do KD. The role and efficacy of exercise in persons with Cancer. PM\&R. 2012;4(11):874-81.

13. Jones LW, Eves ND, Haykowsky M, Freedland SJ, Mackey JR. Exercise intolerance in cancer and the role of exercise therapy to reverse dysfunction. Lancet Oncol. 2009:10(6):598-605.

14. Okwuosa TM, Anzevino S, Rao R. Cardiovascular disease in cancer survivors. Postgrad Med J. 2017:93(1096):82

15. Buttigliero C, Vana F, Bertaglia V, Vignani F, Fiori C, Osella G, et al. The fat body mass increase after adjuvant androgen deprivation therapy is predictive of prostate cancer outcome.(Report) (Author abstract). Endocrine. 2015;50(1):223.

16. Huy C, Schmidt ME, Vrieling A, Chang-Claude J, Steindorf K. Physical activity in a German breast cancer patient cohort: one-year trends and characteristics associated with change in activity level. Eur J Cancer. 2012; 48(3):297-304

17. Rock C, Doyle C, Demark-Wahnefried W, Meyerhardt J, Courneya K, Schwartz A, et al. Nutrition and physical activity guidelines for cancer survivors. Ca : a Cancer Journal for Clinicians. 2012:62(4):242

18. van Waart H, Stuiver MM, van Harten WH, Geleijn E, Kieffer JM, Buffart LM, et al. Effect of low-intensity physical activity and moderate- to high-intensity physical exercise during adjuvant chemotherapy on physical fitness, fatigue, 
and chemotherapy completion rates: results of the PACES randomized clinical trial. J Clin Oncol. 2015;33(17):1918-27.

19. Galvao DA, Newton RU. Review of exercise intervention studies in cancer patients. J Clin Oncol. 2005;23(4):899-909.

20. Servaes $P$, Verhagen $C$, Bleijenberg G. Fatigue in cancer patients during and after treatment:prevalence, correlates and interventions: prevalence, correlates and interventions. Eur J Cancer. 2002;38(1):27-43.

21. Bower JE, Bak K, Berger A, Breitbart W, Escalante CP, Ganz PA, et al. Screening, assessment, and management of fatigue in adult survivors of cancer: an American Society of Clinical oncology clinical practice guideline adaptation. Journal of clinical oncology : official journal of the American Society of Clinical Oncology. 2014;32(17):1840.

22. Adamsen L, Quist M, Andersen C, Møller T, Herrstedt J, Kronborg D, et al. Effect of a multimodal high intensity exercise intervention in cancer patients undergoing chemotherapy: randomised controlled trial. BMJ. 2009;339.

23. Berntsen S, Aaronson N, Borjeson S, Demmelmaier I, Hellbom M, Hojman P, et al. Design of a randomized controlled trial of physical training and cancer (Phys-can) - the impact of exercise intensity on cancer related fatigue, quality of life and disease outcome. BMC Cancer. 2017;17.

24. Book of Abstracts of the 24th Annual Congress of the European College of Sport Science - 3rd - 6th July 2019, Prague - Czech Republic. The 24th annual Congress of the EUROPEAN COLLEGE OF SPORT SCIENCE; 2019 3-6 july 2019 Prague - Czech Repuplic: European College of Sport Science; 2019

25. Borg G. Perceived exertion as an indicator of somatic stress. Scand J Rehabil Med. 1970;2(2):92-8.

26. ATS/ACCP statement on cardiopulmonary exercise testing. Am J Respir Crit Care Med2003. p. 211-277.

27. St-Onge M, Mignault D, Allison DB, Rabasa-Lhoret R. Evaluation of a portable device to measure daily energy expenditure in free-living adults. Am J Clin Nutr. 2007:85(3):742.

28. Berntsen S, Hageberg R, Aandstad A, Mowinckel P, Anderssen SA, Carlsen $\mathrm{KH}$, et al. Validity of physical activity monitors in adults participating in freeliving activities. Br J Sports Med. 2008;44(9):657-64.

29. Cereda E, Turrini M, Ciapanna D, Marbello L, Pietrobelli A, Corradi E. Assessing energy expenditure in Cancer patients: a pilot validation of a new wearable device. JPEN J Parenter Enteral Nutr. 2007;31(6):502-7.

30. Garber CE, Blissmer B, Deschenes M, Franklin BA, Lamonte M, Lee I, et al, Quantity and quality of exercise for developing and maintaining cardiorespiratory, musculoskeletal, and Neuromotor fitness in apparently healthy adults: guidance for prescribing exercise. Med Sci Sports Exerc 2011;43(7):1334-59.

31. Smets EM, Garssen B, Bonke B, De Haes JC. The multidimensional fatigue inventory (MFI) psychometric qualities of an instrument to assess fatigue. Psychosom Res. 1995;39(3):315-25.

32. Hagelin $\mathrm{CL}$, Wengstrom $\mathrm{Y}$, Runesdotter $\mathrm{S}$, Furst $\mathrm{CJ}$. The psychometric properties of the Swedish multidimensional fatigue inventory MFI-20 in four different populations. Acta Oncol. 2007;46(1):97-104.

33. Purcell A, Fleming J, Bennett S, Burmeister B, Haines T. Determining the minimal clinically important difference criteria for the multidimensional fatigue inventory in a radiotherapy population. Support Care Cancer. 2010; 18(3):307-15.

34. Hosmer DW, Lemeshow S. Applied logistic regression. 2nd ed. ed. New York: Wiley; 2000.

35. Lee WJ, Kerry SC, John RM, Hyman BM, Edith NP, Jessica MS, et al. Cardiopulmonary function and age-related decline across the breast Cancer survivorship continuum. J Clin Oncol. 2012;30(20):2530.

36. Jones LW, Haykowsky M, Pituskin EN, Jendzjowsky NG, Tomczak CR, Haennel RG, et al. Cardiovascular reserve and risk profile of postmenopausal women after chemoendocrine therapy for hormone receptor--positive operable breast cancer. Oncologist. 2007;12(10):1156.

37. Edvardsen E, Hansen BH, Holme IM, Dyrstad SM, Anderssen SA. Reference values for cardiorespiratory response and fitness on the treadmill in a 20- to 85-year-old population. Chest. 2013;144(1):241-8.

38. Kenk M, Thackeray J, Thorn S, Dhami K, Chow B, Ascah K, et al. Alterations of pre- and postsynaptic noradrenergic signaling in a rat model of adriamycin-induced cardiotoxicity. J Nucl Cardiol. 2010;17(2):254-63.

39. Hayward R, Hydock D, Gibson N, Greufe S, Bredahl E, Parry T. Tissue retention of doxorubicin and its effects on cardiac, smooth, and skeletal muscle function. Official Journal of the University of Navarra, Spain. 2013; 69(2):177-87.
40. Hydock DS, Lien C-Y, Jensen BT, Schneider CM, Hayward R. Characterization of the effect of in vivo doxorubicin treatment on skeletal muscle function in the rat. Anticancer Res. 2011;31(6):2023.

41. Chicco A, Hydock D, Schneider CM, Hayward R. Low-intensity exercise training during doxorubicin treatment protects against cardiotoxicity. J Appl Physiol. 2006;100(2):519-27.

42. Jones L, Courneya K, Fairey A, Mackey J. Effects of an oncologist's recommendation to exercise on self-reported exercise behavior in newly diagnosed breast cancer survivors: a single-blind, randomized controlled trial. Ann Behav Med. 2004;28(2):105-13.

43. Courneya KS, Segal RJ, Gelmon K, Reid RD, Mackey JR, Friedenreich CM, et al. Predictors of supervised exercise adherence during breast cancer chemotherapy. Med Sci Sports Exerc. 2008;40(6):1180.

44. Jones LW, Eves ND, Haykowsky M, Joy AA, Douglas PS. Cardiorespiratory exercise testing in clinical oncology research: systematic review and practice recommendations. Lancet Oncol. 2008;9(8):757-65.

45. Vassbakk-Brovold K, Berntsen S, Fegran L, Lian H, Mjåland O, Mjåland S, et al. Lifestyle changes in cancer patients undergoing curative or palliative chemotherapy: is it feasible? Acta Oncol. 2017:1-8.

46. Jones LW, Courneya KS, Mackey JR, Muss HB, Pituskin EN, Scott JM, et al. Cardiopulmonary function and age-related decline across the breast cancer survivorship continuum. Journal of clinical oncology : official journal of the American Society of Clinical Oncology. 2012;30(20):2530.

47. Steins Bisschop C, Velthuis M, Wittink H, Kuiper K, Takken T, Meulen W, et al. Cardiopulmonary exercise testing in Cancer rehabilitation. Sports Med. 2012; 42(5):367-79.

48. Wall $A B$, Galvão AD, Fatehee RN, Taaffe UD, Spry UN, Joseph UD, et al. Maximal exercise testing of men with prostate Cancer being treated with androgen deprivation therapy. Med Sci Sports Exerc. 2014;46(12):2210-5.

49. Lakoski S, Barlow C, Koelwyn G, Hornsby W, Hernandez J, DeFina L, et al. The influence of adjuvant therapy on cardiorespiratory fitness in early-stage breast cancer seven years after diagnosis: the Cooper Center longitudinal study. Breast Cancer Res Treat. 2013;138(3):909-16.

\section{Publisher's Note}

Springer Nature remains neutral with regard to jurisdictional claims in published maps and institutional affiliations.

Ready to submit your research? Choose BMC and benefit from

- fast, convenient online submission

- thorough peer review by experienced researchers in your field

- rapid publication on acceptance

- support for research data, including large and complex data types

- gold Open Access which fosters wider collaboration and increased citations

- maximum visibility for your research: over $100 \mathrm{M}$ website views per year

At BMC, research is always in progress.

Learn more biomedcentral.com/submissions 